\title{
Intervenção Educacional na área da área através de objetos de aprendizagem: um relato de experiência
}

\author{
Ana Amélia N.S. Bones ${ }^{1}$, Silvio C. Cazella ${ }^{2}$, Márcia R. Costa ${ }^{3}$ \\ ${ }^{1}$ Mestranda- Ensino na Saúde-UFCSPA- Universidade Federal de Ciências da Saúde de Porto Alegre² UFCSPA- \\ Universidade Federal de Ciências Médicas de Porto Alegre \\ ${ }^{3}$ UFCSPA- Universidade Federal de Ciências Médicas de Porto Alegre e UNASUS/ UFCSPA \\ \{anageriatra@hotmail.com, silvioc.ufcspalgmail.com, \\ marciarc.ufcspa@gmail.com\}
}

\begin{abstract}
The module of the Patient's Initial Treatment for the rapid HIV reacting testing was developed with the aim at making it possible the approach of the aspects of a wholly attendance, allowing the construction and improvement of feasible flows of attendance to the patients. This article presents a pedagogical intervention that was planned in a way of a learning object by a multiprofessional team, acting on the interdisciplinary way, applying an active methodology named Problematization Methodology, with focus on the student's expected competences in the course inside the Distance Learning mode, where it is shown the alternative of how the competences were structured into the steps of the planning and the application of this module.
\end{abstract}

Resumo. O módulo do Manejo Inicial do Usuário com Teste Rápido Reagente para o Virus do HIV foi desenvolvido com o objetivo de possibilitar a abordagem aos aspectos de atendimento integral, permitindo a construção e aprimoramento dos fluxos viáveis de atendimento ao paciente. Este artigo apresenta uma intervenção educacional que foi concebida na forma de objeto de aprendizagem, por uma equipe multiprofissional atuando de forma interdisciplinar, utilizando uma metodologia ativa denominada Metodologia da Problematização, com o foco nas competências esperadas do aluno no curso na modalidade Educação a Distância, apresentando-se a alternativa de como foram planejadas as competências nas etapas de elaboração e aplicação.

\section{Introdução}

Este artigo aborda a construção de um objeto de aprendizagem (OA) para utilização em um módulo de ensino na área da saúde ministrado na modalidade de educação à distância (EaD) focado em competências, desde sua concepção pelo conteudista até a sua aplicação aos profissionais da atenção primária em saúde. $\mathrm{O}$ desafio proposto exige cooperação entre a área de Tecnologia da Informação e várias outras áreas do conhecimento, como as vinculadas à Saúde e à Pedagogia. Cada uma destas engloba um conjunto de saberes e expertise. $\mathrm{O}$ escopo do trabalho é relatar a experiência da equipe interdisciplinar ao planejar quais competências devem o OA permitir ser desenvolvidas desde o início, a fim de facilitar o processo de ensino e aprendizagem a partir de um referencial teórico. O OA produzido constituiu-se o módulo educacional optativo sobre o Manejo de Usuários com o Teste Rápido Reagente para HIV na Atenção Primária em Saúde, com duração de 8 horas. Disponibilizado para médicos em formação na Especialização de Saúde da Família do 
V Congresso Brasileiro de Informática na Educação (CBIE 2016)

Anais do XXII Workshop de Informática na Escola (WIE 2016)

UNA-SUS/ UFCSPA e acessível através da Plataforma ARES UNA-SUS, com registro 3474.

$\mathrm{O}$ contexto nacional da modalidade de ensino em EaD na Medicina vivencia a expansão de programas e cursos de formação continuada em serviço de profissionais de diversas áreas de atuação. A EaD direcionada a profissionais da saúde vinculados ao Sistema Único de Saúde (SUS) apresenta-se como uma estratégia na sua formação permanente, a qual pode, através da disponibilidade das Tecnologias de Informação e Comunicação (TICs), aprimorar a sua prática social.

O artigo 200, da Constituição Federal de 1988, em seu inciso III, atribui ao SUS a competência de ordenar a formação na área da Saúde, conforme publicado em Brasil (1998). O Ministério da Saúde tem desenvolvido, ao longo do tempo, várias estratégias e políticas voltadas para a adequação da formação e qualificação dos trabalhadores de saúde às necessidades de saúde da população e ao desenvolvimento do SUS. A oportunidade de participar de espaços educacionais orientados a discutirem não só conhecimentos científicos, mas desafios e obstáculos, possibilitam ampliar o olhar à rede de cuidado integrado às necessidades de saúde. Para legitimar a necessidade de emprego de ambientes virtuais de aprendizagem, remete-se à realidade brasileira da concentração de núcleos de formação em saúde em grandes centros urbanos. Assim, justifica-se a busca de ferramentas para o desenvolvimento de processos educacionais que sejam efetivamente orientados pelos princípios da Educação Permanente em Saúde no contexto nacional, podendo exemplificar com dois grandes programas de especialização em Saúde da Família de abrangência nacional que utilizam a EaD: o Mais Médicos e o PROVAB.

Neste cenário vislumbram-se que as especificidades da $\mathrm{EaD}$ mediadas por computador requerem que os seus participantes possuam Conhecimentos, Habilidades e Atitudes (CHA) adequadas para essa forma de aprendizagem, os quais podem ser designados como competências específicas como descrito por Behar (2013). Desta maneira, tanto para docente quanto para discente pressupõe-se um domínio no uso da tecnologia e de suas possibilidades. O cerne de nosso trabalho está inicialmente na definição de competências, o conhecimento de suas categorias aplicadas aos discentes em EaD e possibilidades de seu emprego consciente em OA na área da saúde.

A formação na modalidade EaD promovida por instituições de ensino oferece uma perspectiva de padronização de conteúdos educacionais transmitidos à longa distância, contribuindo para uma prática de ensino baseada em evidências. Deste modo, evita-se a distorção ou perda de conteúdos como descrito por Ogakawa (2013). No entanto, Leite (2010) observa que na área da saúde existe uma grande variabilidade de assuntos e enfoques. Muitos recursos podem ser otimizados se a proposta de intervenção estiver afinada com o público alvo. Conhecimentos científicos, recursos tecnológicos avançados e alto grau de exigência dos profissionais da saúde necessitam de uma proposta pedagógica que crie um diálogo entre as áreas de conhecimento. Assim, com a construção de ações educativas na educação médica estimula-se a formação reflexiva e evita-se a simples reprodução do conhecimento como apontado por Oliveira (2007).

A partir do levantamento bibliográfico, relata-se a experiência vivida pelos autores, especialmente na concepção e aplicação do módulo sobre o Manejo do usuário com teste rápido reagente para $\mathrm{HIV}$ na Atenção Primária em Saúde ofertado no Curso de 
Especialização de Saúde da Família da UNA-SUS/ UFCSPA. Definiu-se como objetivo deste artigo discutir sobre a reflexão de quais competências digitais relevantes os discentes devem possuir para poderem utilizar esta modalidade de ensino de modo eficiente na sua formação. A construção deste texto tem como finalidade contribuir como um referencial de apoio e de entendimento dos conceitos relacionados à EaD, quando aplicada à formação permanente e à analise de competências.

E estabeleceu-se uma sequência na estruturação das seções deste artigo, iniciando com uma análise sobre competências, seguido pela apresentação das competências necessárias ao aluno no curso em modalidade EaD e metodologia. Finaliza-se o artigo apresentando-se uma alternativa de como serem planejadas as competências nas etapas de elaboração e aplicação do módulo.

\section{Competências}

O termo competências pode ser empregado no sentido de uma formação integral dos alunos considerando-se três elementos, os quais são: conhecimentos, habilidades e atitudes (CHA). $\mathrm{O}$ delineamento de recursos como modo de suporte e energia para os referidos elementos são definidos como recursos interligados de suporte, de mobilização e evolução. A seleção e intensidade de cada recurso empregado em cada instante são decididas pelo sujeito psicológico gerando respostas inéditas, criativas e eficazes para novos problemas conforme pesquisado por Behar (2013) e Ferreira (2013).

Faz-se necessário, antes de aprofundar o assunto, buscar a compreensão do significado do que é competência. Na base dessa tríade de elementos já mencionados são discutidos os pressupostos teóricos, tecnológicos e metodológicos das competências na perspectiva da EaD. Dessa forma, Okagawa (2013) infere que as competências são a capacidade de mobilizar conhecimentos a fim de se enfrentar uma determinada situação, em que o termo deve ser empregado sempre no plural, em razão do entendimento que não há desenvolvimento de competências absolutas, mas várias desenvolvidas e em desenvolvimento.

Machado (2007) ressalta que somente pessoas podem ser competentes, apesar de se atribuir muitas vezes inadequadamente este adjetivo a objetos, a artefatos ou a animais. Outros elementos fundamentais para constituir a noção da natureza da competência são: âmbito, mobilização, conteúdo, abstração e integridade. Acrescenta-se que existe a necessidade de realizar junto com outros indivíduos, se integrar, e que a ausência de conhecimento é o primeiro sinal de incompetência. Ainda que, não existem competências sem concretizar uma ação efetiva. Ao assumir, competências, como capacidade de agir eficazmente num determinado contexto, estruturado em conhecimentos, mas não restrita a estes, Perrenoud (1999) transporta a ideia que poderia ser aplicado o conceito para o papel potencial do aluno e do professor no processo cíclico de Aprendizagem-EnsinoAprendizagem. Mendes (2015) correlaciona que os professores mais velhos têm mais interesse pelo uso da informática na educação do que os mais jovens, apoiado no contexto de um curso de extensão a distância de formação docente para a produção de OAs.

Perrenoud (1999) é um dos precursores da discussão do atual conceito de competência, definindo-a como a aptidão de mobilizar diversos recursos cognitivos (saberes, capacidades, informações, etc) a fim de resolver com pertinência e eficácia uma série de situações. Definir a diferença entre competência e habilidade é primordial. Para a 
melhor resposta possível para uma situação necessita-se, de regra, pôr em ação e em sinergia vários recursos cognitivos complementares, entre os quais estão os conhecimentos. A competência administra um conjunto de esquemas de percepção, pensamento, avaliação e ação; enquanto a habilidade é menos ampla, sendo um elemento do CHA. Por conseguinte, Behar (2013) define que habilidade constitui um dos componentes das competências, sendo que uma mesma habilidade pode estar presente em diversas competências. De acordo com Lê Borterf (2006), a construção da competência ocorre com a capacidade de mobilizar diversos tipos de recursos cognitivos, entre os quais estão as informações e os saberes: saberes pessoais, privados ou saberes públicos, simples compartilhados; saberes acadêmicos, saberes profissionais, saberes de senso comum; saberes provenientes da experiência, de uma troca, ou saberes adquiridos na etapa de formação; saberes de ação, pouco formalizados; e, saberes teóricos, baseados na pesquisa. A sua argumentação contempla que é de contingência do profissional saber executar além do prescrito, devendo criar, reconstruir e inovar. A competência, portanto, não é formada apenas por saberes, mas também por esquemas que permitem sua mobilização, assim como por esquemas de ação que as não utilizam necessariamente. Considera-se que cada etapa de um processo necessita de uma nova avaliação para a retomada de ações, considerando saber agir com pertinência, mobilizar saberes e conhecimentos em um contexto profissional, integrar ou combinar saberes múltiplos e heterogêneos, transpor, aprender, aprender a aprender e envolver-se.

Lê Borterf (2006) discute a relevância do dispositivo de avaliação do profissional que é designado como competências, pois as mesmas são invisíveis e não estão diretamente acessíveis para serem contabilizadas. A interpretação da prática que o profissional recorre das prescrições de trabalhos a serem realizados está associada aos conceitos de metodologia utilizados, aos autores e seus pontos de vista envolvidos. Assim, o mesmo autor remete ao questionamento em que avalia se o sujeito age de forma competente ou se possui as competências, mostrando a necessidade de compreensão do significado destes termos antes de qualquer discussão. Medir competências por apenas resultados deve ser avaliado com cautela. $\mathrm{O}$ ator deve ser capaz de investir seus conhecimentos e experiências com discernimento, de relacioná-los a situações, de transpô-los e enriquecê-los, sendo recrutados no momento de agir. Muitas vezes, essa mobilização deve ser realizada em situações de urgência, devendo rapidamente estabelecer algumas conexões essenciais e o indivíduo não dispõem de tempo de pesquisar em uma fonte confiável. Contudo, Perrenoud (2001) refere que a ação não se estrutura somente em saberes, mesmo nas situações de atos racionais baseados em uma teoria repleta de dados complexos, pois existe o pensamento que opera sobre os saberes que não são saberes, como refletir, concluir, tomar decisões e transformar em ações. A partir da concepção de competências entre diversos pesquisadores realiza-se um diagnóstico da necessidade de refletir sobre a educação permanente dos profissionais da saúde vinculados ao SUS, na modalidade EaD. A proposta perpassa a formação tradicional de capacitar sobre os conteúdos específicos e através de metodologias adequadas para estimular o aprimoramento de competências necessárias para sua prática.

\section{Competências com Foco no Aluno da EaD}

Os contextos relativamente recentes da implantação da EaD na educação permanente e da discussão das competências no campo da educação em saúde se somam em poucas produções científicas no momento, apesar da relevância do tema. O núcleo NUTED da UFRGS tem expandido pesquisas sobre os assuntos relacionados ao perfil de competências 
dos atores na $\mathrm{EaD}$ e às suas metodologias de ensino. $\mathrm{O}$ mapeamento de competências com foco no aluno da EaD elencou 12 competências para o melhor uso deste tipo de modalidade de ensino através do desenvolvimento e aplicação de um objeto de aprendizagem. Behar (2013) analisa a partir dos alunos da EaD quais as competências necessárias para esta modalidade. Esta pesquisa aponta que assim como o discente na sala de aula precisa ter competências que o possibilite atuar como estudante, o da EaD também requer competências apropriadas para enfrentar os desafios da proposta à distância. Ainda na educação, Machado (2007) esclarece que apesar da ambivalência semântica das palavras competência e competição, existe a proposta que esta associação não deva ocorrer, visto que a primeira busca o conhecimento coletivo, objetivando o bem comum e todos podem sair vencedores. Diferindo de competição que se prevê rivalidade e expectativa de, em comum acordo, a aceitação de regra de um vencedor. Segundo Behar (2013), a organização das doze competências digitais conforme sua descrição e suas características de acordo com os elementos formadores do CHA: administração do tempo, reflexão, fluência digital, organização, autonomia, planejamento, comunicação, presencialidade virtual, auto avaliação, organização, automotivação e trabalho em equipe. Enquanto que Ferreira (2013) elenca 21 competências digitais no relatório final da DIGCOMP atribuídas aos cidadãos europeus, distribuídas nos grupos: informação, comunicação, desenvolver conteúdos, agir com segurança e resolver problemas.

Considerando que ambientes virtuais de aprendizagem demandam de fluência digital, é importante avaliar qual o perfil do aluno que compõe a comunidade a ser proposta e a necessidade das competências elencadas pelo professor a serem trabalhadas pelo aluno. Cazella (2011) trabalha sistemas de recomendação de OAs com base em competências específicas a serem desenvolvidas pelos alunos, escolhidas pelo docente conforme este planeja aprimorar com os alunos e o perfil da turma. O mecanismo aciona a filtragem de informação, selecionando os OAs a serem recomendados aos alunos, com base em seu perfil e as competências que o mesmo tem de desenvolver com o uso do OA. Assim, se o OA pertencer a um repositório que considere estas características, facilita no planejamento pedagógico para que o objeto seja reutilizado, e na escolha didática o educador encaminhe ao aluno o conteúdo (OA) que melhor atenda a sua necessidade de competência a ser desenvolvida.

\section{Metodologia}

A metodologia da pesquisa se constitui por pesquisa bibliográfica e observação in loco, da produção e desenvolvimento do OA focado em competências. No módulo do Manejo Inicial do Usuário com Teste Rápido Reagente para o Vírus do HIV, o referido OA foi desenvolvido com o objetivo de possibilitar aos profissionais da Atenção Primaria em Saúde abordarem os aspectos de atendimento integral no momento diagnóstico, permitindo a construção e aprimoramento dos possíveis fluxos de atendimento aos pacientes. A complexidade da atenção às diversas etapas da concepção à aplicação do OA requer a organização do processo de trabalho com o escopo da prática colaborativa na integralidade do projeto educacional, lançando às equipes multiprofissionais o desafio da construção de uma prática interdisciplinar na autoria e aplicação do OA.

Segundo análise de Amiel e Amaral (2013), o docente, ciente de seu papel, pode e deve utilizar-se de sua prática como trabalhador ao orientar o aluno, auxiliando a compreender e agir diante da complexidade do sistema tecnológico. Iribarry (2003) aponta a 
interdisciplinaridade como um passo além do fazer multiprofissional, onde há a interação das disciplinas em dois níveis hierarquizados, sendo o nível superior o coordenador e integrador das disciplinas, em busca de um objetivo comum. Portanto, uma discussão acerca do termo interdisciplinaridade pressupõe novas formas de relacionamento, onde o coordenador assume o papel de administração e tomada de decisões, após o processo de interação entre as demais áreas profissionais. A interdisciplinaridade não nega o aprofundamento das áreas de conhecimento, mas realiza uma crítica quando aponta que a fragmentação das disciplinas impossibilita realizar ações resolutivas que respondam às situações- problema no cotidiano da vida humana.

\section{O Objeto de Aprendizagem}

$\mathrm{Na}$ nossa experiência, o profissional da informação assume a coordenação do projeto, conduzindo o trabalho em equipe com demais membros da área da Computação, Design Gráfico, Pedagogia e Medicina. A interseção dos conhecimentos e realização das tarefas permitiram um diálogo estratégico ao longo de todo o projeto, o que permitiu pensar no desenvolvimento de competências em todas as etapas. Na sequência, relatamos a reflexão desta trajetória da concepção a aplicação do OA com foco em competências dos alunos da $\mathrm{EaD}$, na seguintes etapas: escolha do conteúdo, o plano pedagógico, o storyboard, produção/ design do módulo e sua aplicação.

A escolha da temática de manejo de usuários no momento do diagnóstico de infeção pelo vírus do HIV na Atenção Primária de Saúde se deve pela necessidade de aprimoramento da adoção do novo instrumento que permite testar o indivíduo dentro da unidade de saúde, o qual fornece o resultado em 30 minutos, chamado de Teste Rápido de HIV . A Portaria $\mathrm{N}^{\mathrm{o}} 3.275$, de 26 dezembro de 2013, considerando a necessidade de se criar alternativas para a ampliação do acesso ao diagnóstico desta infecção, em atendimento aos princípios da equidade e da integralidade da assistência, bem como da universalidade de acesso aos serviços de saúde do SUS resolve incentivar a possibilidade de treinamentos por meio de cursos de ensino à distância, para realização da metodologia, de acordo com as diretrizes estabelecidas pelo Departamento de DST, Aids e Hepatites Virais. Como o módulo foi oferecido de forma optativa na plataforma do curso de especialização $\mathrm{EaD}$, o aluno deve apresentar interesse pelo assunto, motivação e autonomia, tendo um comportamento pró ativo em se inscrever.

O conteudista, no caso o profissional médico com expertise em HIV, elaborou um plano pedagógico com auxílio da coordenação pedagógica a fim de estabelecer as etapas do projeto da concepção do OA. A primeira etapa foi definição da ementa e das competências da unidade educacional, carga horária estimada para sua execução e público alvo. Após, estabeleceu-se os objetivos da aprendizagem e os conteúdos a serem abordados ao longo do módulo. O emprego da Metodologia da Problematização (MP) foi pela premissa descrita pela sua autora Berbel (1998) que a MP baseia-se na superação de obstáculos, através da identificação e construção de possibilidades de solução a Realidade mediadas pelo professor, no caso Tutor. A abordagem deste tema desafiador na saúde na EaD com este tipo de Metodologia Ativa, requer o estimulo das competências de autonomia, reflexão, motivação e trabalho de equipe. No plano pedagógico, as propostas das atividades percorreram as cinco etapas do Arco de Maguerez e os objetivos foram além da assimilação de conteúdos, promovendo aprendizagem significativa através da adoção da MP e desenvolvendo a autonomia dos sujeitos e a corresponsabilização no seu processo de trabalho em equipe, de acordo com o designo da MP. 
A elaboração de storyboard apoia o planejamento da ação pedagógica de forma gráfica, o conteudista informa visualmente todas as etapas da modulação do OA, estabelecendo um roteiro para nortear o design gráfico sobre como programar ou incluir cada recurso, ferramenta, atividade e animação. $\mathrm{O}$ uso do storyboard facilitou o processo de organização dos elementos na tela e facilitou a comunicação no desenvolvimento da instrução tornando o trabalho mais eficiente, uma vez que auxilia na criação de novos elementos tornando as experiências dos alunos mais envolventes e visualmente ricas. A fluência digital é uma competência que se espera do aluno em razão do mesmo estar integrado no sistema de aprendizagem da plataforma, estando digitalmente ativo ao longo deste módulo. Além da fluência digital, a presencialidade virtual, a comunicação, a reflexão e o trabalho em equipe foram competências fundamentais aos alunos no processo ensino aprendizagem do OA.

Schuelter (2015) apresenta a seguir os pontos a serem pensados para organizar objetos por competências que têm sido estudados na FabriCO Educare, em fase de aprimoramento. $\mathrm{Na}$ concepção, além de toda proposição pedagógica para o desenvolvimento dos materiais didáticos de um curso, estes alinham para que os OAs sejam separados por competências, oficializadas em todos os guias de produção. $\mathrm{Na}$ redação, salientam-se a importância de trabalhar a redação dos conteúdos de forma que existam itens de ligação entre diferentes competências. Esta prática permite que os objetos sejam divididos por competências distintas. Já no design educacional, se produzem os roteiros dos OAs independentemente da mídia produzida, organizado por competências. Enquanto na produção de mídias, a proposta de organização dos objetos já está prevista e o conteúdo todo organizado, observando criteriosamente as propostas feitas nas fases anteriores.

Na nossa intervenção, os recursos utilizados no eixo central do módulo aparecem relacionados ao caso clínico complexo Alisson na cidade virtual de Santa Fé, utilizando a elaboração de recursos fictícios pela equipe de design e produção de áudio da campanha na rádio, imagem de banner e reportagem de jornal local. A estratégia de organização do material didático na forma de OA foi sendo concebida assumindo como pressuposto que é possível organizar de forma pedagógica materiais de domínio público, disponibilizados por instituições reconhecidas no tratamento do HIV.

As avaliações da aprendizagem do OA foram distribuídas ao longo do módulo segundo a metodologia de ensino, a MP. Iniciando com Fórum onde os alunos necessitaram das competências de comunicação, reflexão, presencialidade e trabalho em equipe para discutir entre seus pares sobre a orientação do seu tutor a partir da pergunta disparadora. A figura 1 apresenta a interface da animação em que uma figura humana representa $\mathrm{O}$ profissional da saúde, com as perguntas disparadoras. Ao lado, existe a orientação da atividade, estimulando a comunicação, a reflexão, o trabalho de equipe e a presencialidade. A etapa chamada de Teorização (figura 2) é marcada pelas competências da autonomia e da flexibilidade, pois além das leituras obrigatórias, o aluno é convidado a explorar outras fontes consolidadas de referencial teórico. $\mathrm{O}$ intuito é transformar o discente em um pesquisador para auxiliar na solução dos problemas que surgirem na sua prática profissional, podendo intervir na sua realidade, como o proposto dela autora da MP, descrito em Berbel (1998). 
V Congresso Brasileiro de Informática na Educação (CBIE 2016)

Anais do XXII Workshop de Informática na Escola (WIE 2016)

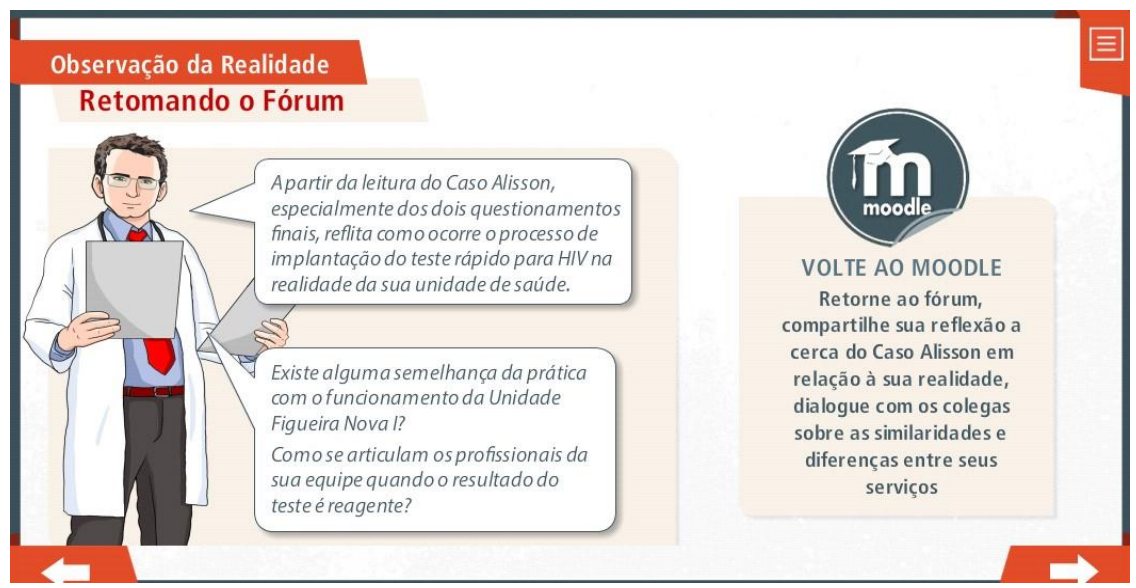

Figura 1. Interface com a animação do OA referente à Teorização.

Fonte: Próprio Autor

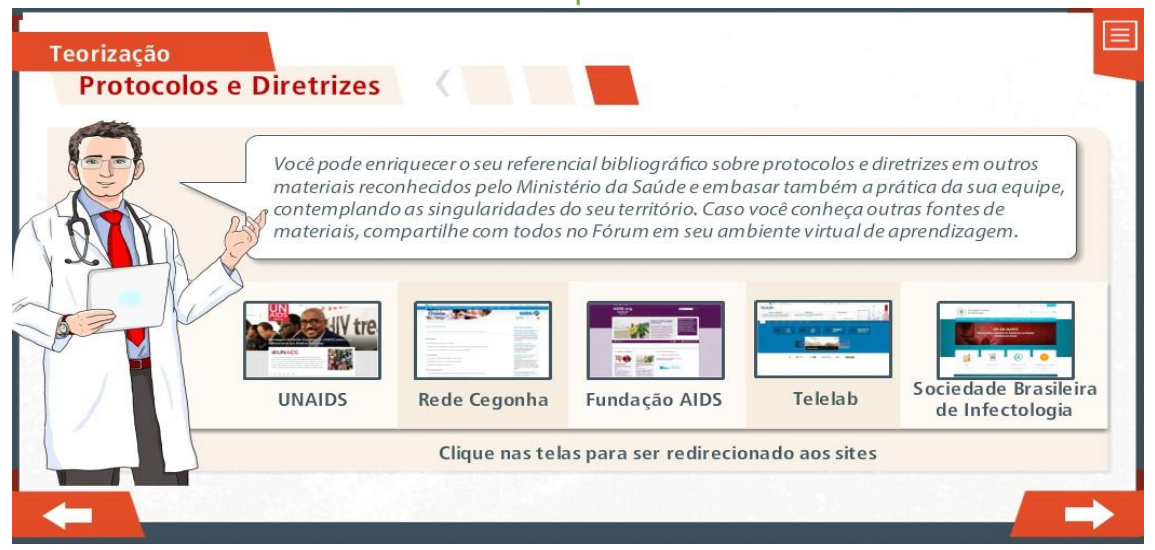

Figura 2. Interface com a animação do OA referente à Teorização.

Fonte: Próprio Autor

Entre as atividades avaliativas, as com maior destaque dentro do OA são as soluções propostas em formato de texto pelo aluno, que requer, principalmente, as competências de reflexão e comunicação e a construção do fluxograma para aprimorar o manejo inicial do paciente com resultado reagente dentro da própria unidade de saúde que aciona também as competências de auto avaliação e trabalho em equipe. Tavares $(2007,2010)$ apresenta o fluxograma como um tipo de mapa conceitual, que ao ser utilizado no processo de aprendizagem de determinado tema, possibilita ao estudante construir seu conhecimento, ao fazer conexões importantes entre significados e desse modo possibilita a sua aprendizagem significativa.

\section{Considerações Finais}

Ressaltamos que as informações apresentadas são uma reflexão sobre a experiência da concepção à aplicação da intervenção educacional sobre a delicada temática da revelação diagnóstica e manejo inicial do paciente com HIV, na proposta de educação permanente em saúde, com foco nas competências necessárias aos discentes para o uso adequado da modalidade EaD. O cotidiano da prática de ensino mediada pelo computador através dos módulos educacionais requer implicitamente competências digitais aos seus alunos. O exercício proposto foi fazer a reflexão sobre as mesmas ao longo da trajetória deste OA de modo interdisciplinar numa equipe multiprofissional. 
Apesar desta maior disponibilidade da informação e conhecimento facilitado pela modalidade EaD ainda é necessário refletir sobre o significado de competências, sobre quais são necessárias para que os discentes possam realmente utilizar esta modalidade. Então, percebe-se a necessidade também de refletir sobre aprendizagem e o aprendiz, permeado pelo uso das tecnologias da informação e comunicação integradas às atividades de educação virtual interativa. Assim, será possível a consolidação de pilares nos âmbitos epistemológicos, tecnológicos, pedagógicos e organizacionais, respondendo às necessidades atuais de um novo perfil de aluno, baseado em modelos educacionais inovadores. Espera-se que este artigo sirva como um referencial teórico para apoiar o entendimento dos conceitos relacionados à $\mathrm{EaD}$ aplicada à formação permanente e à análise de competências.

A prática interdisciplinar coloca- se como potencializadora da integração que possibilita uma compreensão ampliada do objeto de trabalho em saúde, por meio da interação entre os profissionais e a articulação entre os diversos saberes e fazeres presentes no trabalho em saúde, possibilitando, deste modo, outras formas de relação entre os sujeitos envolvidos no processo. Iribarry (2003) indica que a multidisciplinaridade se referencia à justaposição de várias disciplinas, ou profissões, sem a exigência de um trabalho coordenado, o que a diferencia da interdisciplinaridade, a qual se refere à solidariedade e compartilhamento de conhecimento e à preocupação do profissional em contribuir com o seu saber objetivando a resolução de um problema. Nesse contexto, a interdisciplinaridade entrou como eixo norteador das ações em saúde, com a proposta de envolver vários segmentos do projeto, possibilitando o diálogo e a construção de saberes e práticas que pautam o fortalecimento no que concerne a consolidação das práticas de promoção da saúde e resolubilidade do sistema. Este artigo trouxe a experiência desenvolvida pelos autores com o intuito de contribuir para estudos da Informática Médica e para a prática da área da $\mathrm{EaD}$ com foco em competências, sendo necessário mais pesquisas sobre o tema para fomentar novas práticas pedagógicas.

\section{Referências}

Amiel, T. and Amaral S.F. (2013) "Nativos e Imigrantes: Questionando o conceito de fluência tecnológica docente" Revista Brasileira de Informática na Educação 21(3),11. Recuperado em 2016 http://www.br-ie.org/pub/index.php/rbie/article/view/1661

Brasil. Constituição (1998). Constituição da República Federativa do Brasil. Brasília, DF: Senado Federal.

Behar, P.A. (2013) Competências em Educação a Distância. Porto Alegre: Editora Penso.

Berbel, N.A. (1998) "A problematização e a aprendizagem baseada em problemas: diferentes termos ou diferentes caminhos?" Interface, 2(2). Recuperado em 2016 http://www.scielo.br/pdf/icse/v2n2/08

Cazella, S.C., Drumm, J.V. e Barbosa, JL. (2010) "Um serviço para recomendação de artigos científicos baseados em filtragem de conteúdo aplicado a dispositivos móveis". Renote, 8(3). Recuperado em 2016 http://seer.ufrgs.br/renote/article/view/18057 
V Congresso Brasileiro de Informática na Educação (CBIE 2016)

Anais do XXII Workshop de Informática na Escola (WIE 2016)

Mendes, A.C., Dante, A. C.e Gimenes, A. M. F. (2015) "Quem tem mais interesse pelo uso da informática na educação? Os professores mais jovens ou os mais velhos?- Um estudo correlacional"(2015) Revista Brasileira de Informática na Educação, 23(2). Recuperado em 2016 http://www.br-ie.org/pub/index.php/rbie/article/view/2903

Ferrari, A. (2013) "DIGCOMP: A Framework for Developing and Understanding Digital Competence in Europe". Recuperado em 2016 http://ftp.jrc.es/EURdoc/JRC83167.pdf

Iribarry, I.N. (2003) "Aproximações sobre a transdisciplinaridade: algumas linhas históricas, fundamentos e princípios aplicados ao trabalho em equipe". Psicol Reflex Crít. 6(3):48390. Recuperado em 2016 http://dx.doi.org/10.1590/S0102- 79722003000300007

Le Boterf, G. (2006) "Avaliar a Competência de um Profissional: três dimensões a explorar". $\begin{array}{lllll}\text { Reflexão } & \text { RH, } & 1(1), 60-3 . & \text { Recuperado } & \text { em }\end{array}$ http://www.guyleboterfconseil.com/Article $\% 20$ evaluation $\% 20$ version $\% 20$ directe $\% 20$ Pes soal.pdf

Leite, M.T.M., Carlini, A.L., Ramos, M.P.e Sigulem, D. (2010) "Educação médica continuada online: potencial e desafios no cenário brasileiro". Revista Brasileira de Educação Medica, 34(1),141-9. Recuperado em 2016 http://www.scielo.br/scielo.php?script=sci_arttext\&pid=S0100-55022010000100017

Machado, N.J. (2006) "Sobre a idéia de competência. In: FEUSP - Programa de Pós Graduação, Seminários de Estudos em Epistemologia e Didática (SEED)". Recuperado em 2016 "http://www.nilsonjosemachado.net/20060804.pdf"

Okagawa, F.S., Bohomol E. e Cunha, I.C.K.O.(2013)"Competências desenvolvidas em um curso de especialização em gestão em enfermagem à distância". Acta Paulista de Enfermagem, 26(3),238-44. Recuperado em 2016 "http://www.scielo.br/scielo.php?script=sci_arttext\&pid=S010321002013000300006 "pid=S0103-21002013000300006

Oliveira, M.A.N. (2007) "Educação à distância como estratégia para a educação permanente em saúde: possibilidades e desafios". Revista Brasileira de Enfermagem, 60(5),585-9. Recuperado em $2016 \mathrm{http} / /$ www.scielo.br/scielo.php?script=sci_arttext\&pid=S003471672007000500019

Perrenoud, P. (1999). Construir as competências desde a escola. Porto Alegre: Editora Artmed.

Schuelter, G. e Guarezi, R. (2015) "Produção de material didático e estudo para reutilizar objetos de aprendizagem buscando por competência". http://www.abed.org.br/congresso2015/anais/pdf/BD_265.pdf, Maio.

Tavares, R. (2010) "Aprendizagem significativa, codificação dual, e objetos de aprendizagem". Revista Brasileira Informática na Educação, 18(2),4-16. Recuperado em 2016 partir de http://www.fisica.ufpb.br/ romero/pdf/2006-IVESUD.pdf

Tavares, R. (2007) "Construindo mapas conceituais". Ciências \& Cognição, 12(0),72-85. Recuperado a partir de http://www.cienciasecognicao.org/pdf/v12/m347187.pdf 